\title{
RENÉ-CHARLES GUILBERT DE PIXÉRECOURT, Mélodrames
}

\section{Lise Sabourin}

\section{Q OpenEdition \\ Journals}

\section{Édition électronique}

URL : https://journals.openedition.org/studifrancesi/31853

DOI : $10.4000 /$ studifrancesi.31853

ISSN : 2421-5856

\section{Éditeur}

Rosenberg \& Sellier

\section{Édition imprimée}

Date de publication : 1 août 2020

Pagination : 412-413

ISSN : 0039-2944

\section{Référence électronique}

Lise Sabourin, « René-Charles GUILbert de PIXÉReCourt, Mélodrames », Studi Francesi [En ligne], 191 (LXIV I

II) | 2020, mis en ligne le 01 septembre 2020, consulté le 18 septembre 2021. URL : http://

journals.openedition.org/studifrancesi/31853; DOI : https://doi.org/10.4000/studifrancesi.31853

Ce document a été généré automatiquement le 18 septembre 2021.

\section{(c)}

Studi Francesi è distribuita con Licenza Creative Commons Attribuzione - Non commerciale - Non opere derivate 4.0 Internazionale. 


\title{
RENÉ-CHARLES GUILBERT DE PIXÉRECOURT, Mélodrames
}

\author{
Lise Sabourin
}

\section{RÉFÉRENCE}

RENÉ-CHARLES GUILBERT DE PIXÉRECOURT, Mélodrames, dir. R. Martin, tome IV, 1809-1810, éd. M. Lemaire, R. Martin et M. Melai, Paris, Classiques Garnier, 2018, 1295 pp.

1 Dans ce quatrième tome des Mélodrames sont présentes trois œuvres de 1809-1810, période assez cruciale du Premier Empire, tant par le remariage de Napoléon pour s'assurer un descendant que par les conflits de la France avec l'Angleterre et l'Espagne. Or justement les trois mélodrames que Pixerécourt va réussir à faire jouer affrontent la censure en rapport avec ces événements.

2 En effet, La Citerne, mélodrame en quatre actes à grand spectacle, se situe durant le Siècle d'or en Espagne et montre, après une mémorable scène de tempête, des pirates pillards d'épaves. Anastasie n'apprécie guère le Français «niais métadramatique», comme le désigne Roxane MARTIN dans sa présentation (pp.21-73), qui affronte le brigand grotesque hérité de Gil Blas. Mais le dramaturge, qui avait déjà envisagé le problème au cours de la gestation de cette «encyclopédie du mélodrame», sait infléchir son personnage avec habileté pour obtenir de créer son œuvre en janvier 1809 au théâtre de la Gaîté, dont il est devenu directeur de scène, chassé qu'il a été de la PorteSaint-Martin par sa fermeture à la suite du décret de 1807, impuissant à faire représenter ses nouvelles œuvres à l'Ambigu-Comique. Le succès est honnête, avec quatre cents représentations à Paris et en province, mais les reprises seront limitées, malgré l'adaptation musicale qu'en tirera Donizetti en 1822. Du moins le Picaros nourrira-t-il l'imaginaire du jeune Hugo qui voit le spectacle à Bayonne en 1811 et y pensera pour créer plus tard son fameux Don César de Bazan!

3 Après avoir écrit un drame lyrique pour l'Opéra-Comique, La Rose blanche et la rose rouge, Pixerécourt reprend le thème de la guerre des deux roses pour imaginer son 
mélodrame Marguerite d'Anjou, également représenté à la Gaité en janvier 1810. En traitant avec liberté des éléments historiques présents dans l'histoire de cette princesse lorraine devenue reine d'Angleterre narrée par l'abbé Prévost en 1740, le dramaturge se heurte encore à la censure, car il évoque la légitimité persécutée de cette mère poursuivie dans la forêt par les troupes yorkistes et sauvée par un brigand, à l'heure du blocus anglais et des débats entre légitimistes et bonapartistes. Qu'à cela ne tienne! Pixerécourt réduit ses répliques, moralise son intrigue et sublime ses personnages français. Maurizio MELAI (présentation, pp. 569-605) et Fernando MORRISON (pour la partition) s'allient afin de restituer la dimension spectaculaire ainsi valorisée, que souligne l'ampleur des didascalies. Le dramaturge montre la Providence à l'œuvre dans un incendie final qui engloutit le traitre de si belle façon que Meyerbeer reprendra son intrigue pour le premier drame lyrique qu'il fera jouer à l'odéon en 1826 (après l'avoir créé avec moins de succès à la Scala en 1820).

Puis Les Ruines de Babylone se situent dans un Irak bien proche du souvenir de l'expédition d'Égypte, avec un Français qui apparaît tel un bouffon dans son défilé militaire sous les yeux du calife Haroun al Raschid. Bien sûr, l'intrigue de ce «nec plus ultra du mélodrame» historique se situe au début du IX ${ }^{\mathrm{e}}$ siècle, mais la question de la préservation de la lignée royale n'est pas éloignée de l'actualité impériale! Il convient donc à l'auteur de filer son intrigue serrée, de multiplier les rebondissements, de mélanger habilement les ambiances, de déployer des scènes pompeuses, des ballets charmants, des costumes somptueux pour détourner l'attention des spectateurs sur ce curieux mariage oriental entre Zaïda, la sœur du calife, et le vizir Giafar à condition de ne pas enfanter. Marion LEMAIRE (présentation, pp. 915-948) et Emma PELLETIER (pour la partition) rendent sensible l'imaginaire du dramaturge qui brode librement à partir d'une tragédie de La Harpe, d'un roman allemand de Klinger sur ces Barmécides et des Mille et une nuits. La création, toujours à la Gaîté en octobre 1810, remporta un vrai triomphe, avec neuf cents représentations à Paris et en province, des reprises ponctuelles jusqu'en 1828, des traductions, une adaptation en opéra-comique par l'auteur lui-même à Bruxelles en 1825 et une parodie en 1827. Là encore Hugo, qui revit le mélodrame avec Nodier en 1826, s'en est inspiré pour son Inèz de Castro dès 1822.

Ces années délicates pour Pixerécourt ont finalement sublimé sa technique mélodramatique, lui permettant d'affiner sa plume pour continuer à poser la question de la légitimité du pouvoir dans son rapport avec le droit, la justice et la vertu. 